\title{
Short-term effects of preoperative beta-blocker use for isolated coronary artery bypass grafting: A systematic review and meta-analysis
}

\author{
Liangshan Wang, MD, Hong Wang, MD, PhD, and Xiaotong Hou, MD, PhD
}

\section{ABSTRACT}

Objective: The use of preoperative beta-blockers has been used as a quality standard for patients undergoing coronary artery bypass grafting (CABG). However, the benefits of beta-blockers use before CABG remain controversial. We performed a systematic review and meta-analysis to investigate the short-term effects of preoperative beta-blocker use for patients undergoing isolated $\mathrm{CABG}$.

Methods: We searched PubMed, Embase, and the Cochrane Library for English articles published from inception to August 16, 2016. Observational studies comparing preoperative beta-blockers therapy or non-beta-blockers therapy were considered eligible for the current study.

Results: Six observational studies with 1,231,850 patients were included. The pooled analyses of unadjusted outcome (odds ratio [OR], 0.82; 95\% confidence interval $[\mathrm{CI}], 0.71-0.95 ; P=.007)$ or risk-adjusted outcome (OR, $0.95 ; 95 \%$ CI, $0.92-0.97 ; P=.000)$ showed slight reduction in operative mortality, whereas an insignificant difference in mortality rate was observed in pooling postoperative data from propensity score analysis (OR, 0.97; 95\% CI, 0.94-1.00; $P=.088$ ). Removing one study that used propensity-score covariate adjustment, subgroup analysis of propensity-matched patients $(313,417$ in each group) still generated a statistically nonsignificant benefit for preoperative beta-blocker use (OR, 0.97; 95\% CI, 0.94-1.00; $P=.093$ ). Furthermore, the preoperative use of beta-blockers did not reduce the incidence of major postoperative complications, such as postoperative myocardial infarction, stroke, atrial fibrillation, reoperation, renal failure, prolonged ventilation, and sternal wound infection.

Conclusions: Our study suggests that the use of preoperative beta-blockers did not reduce either operative mortality or the incidence of postoperative complications in patients undergoing CABG. (J Thorac Cardiovasc Surg 2018;155:620-9)

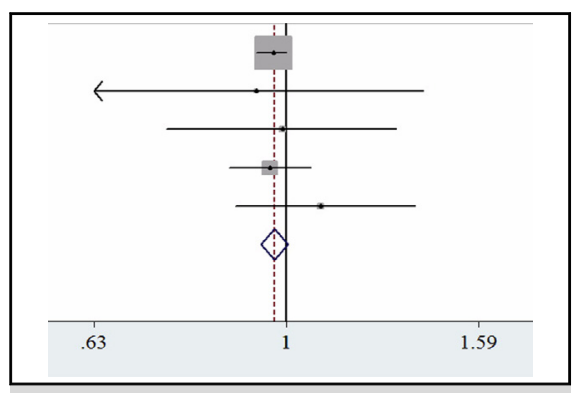

Forest plot of operative mortality outcome from propensity score analysis.

\section{Central Message}

The use of preoperative beta-blockers did not reduce either operative mortality or the incidence of postoperative complications in patients undergoing coronary artery bypass grafting.

\section{Perspective}

The use of preoperative beta-blockers has been used as a quality standard for patients undergoing coronary artery bypass grafting (CABG). However, the benefits of beta-blockers use before $\mathrm{CABG}$ remain controversial. This study suggests that the use of preoperative betablockers does not have short-term benefits for patients undergoing $\mathrm{CABG}$.

See Editorial Commentary page 630.
Currently, coronary heart disease remains the leading cause of death worldwide. ${ }^{1}$ Coronary artery bypass grafting $(\mathrm{CABG})$ remains the standard of care for patients with

\footnotetext{
From the Center for Cardiac Intensive Care, Capital Medical University Affiliated Anzhen Hospital, Beijing, People's Republic of China.

Supported by the Research Foundation of Capital Medical Development (2014-11051 to Dr Hou), the Beijing Municipal Science and Technology Commission (No. Z161100000516017 to Dr Hou), and the National Key Research and Development Program of China (2016YFC1301001 to Dr Hou).

Received for publication Nov 8, 2016; revisions received July 27, 2017; accepted for publication Aug 16, 2017; available ahead of print Sept 13, 2017.

Address for reprints: Xiaotong Hou, MD, PhD, Center for Cardiac Intensive Care, Capital Medical University Affiliated Anzhen Hospital, Beijing, People's Republic of China (E-mail: xt.hou@ccmu.edu.cn).

0022-5223/\$36.00

Copyright $(2) 2017$ by The American Association for Thoracic Surgery

http://dx.doi.org/10.1016/j.jtcvs.2017.08.025
}

complex, multivessel coronary artery disease. ${ }^{2-5}$ In patients with angina, myocardial ischemia commonly results from a prolonged mismatch between oxygen demand and supply. ${ }^{6-8}$ As one of the most commonly used drugs for the treatment of coronary artery disease, beta-blockers can attenuate cardiac ischemia by correcting the imbalance between oxygen demand and supply. ${ }^{7,9,10}$ However, beta-blockers may cause hemodynamic

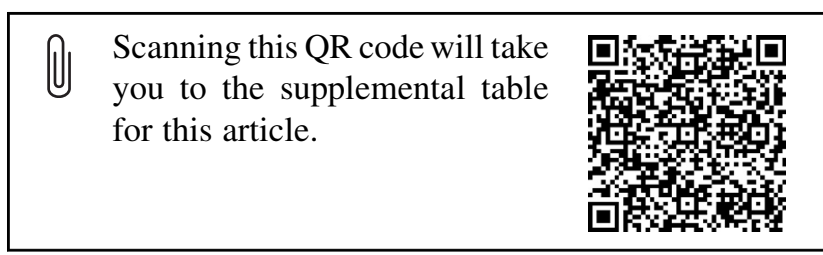




$$
\begin{aligned}
& \text { Abbreviations and Acronyms } \\
& \begin{aligned}
\text { AF } & =\text { atrial fibrillation } \\
\text { CABG } & =\text { coronary artery bypass grafting } \\
\text { CI } & =\text { confidence interval } \\
\text { MI } & =\text { myocardial infarction } \\
\text { OR } & =\text { odds ratio } \\
\text { PSA } & =\text { propensity score analysis } \\
\text { RA } & =\text { risk-adjusted } \\
\text { RCTs } & =\text { randomized controlled trials }
\end{aligned}
\end{aligned}
$$

instability, bronchospasm, and postoperative congestive heart failure, and, consequently, lead to poor prognosis. ${ }^{11,12}$

At present, the effectiveness and safety of preoperative beta-blocker use in patients undergoing isolated CABG remain controversial. In the late 1990s, preoperative beta-blocker use was demonstrated to be associated with a lower operative mortality. ${ }^{13}$ Since 2007, the use of preoperative beta-blockers has been used as a quality standard for patients undergoing CABG ${ }^{14}$ However, there are limited studies investigating the effects of preoperative beta-blocker use for patients undergoing isolated CABG. Indeed, very few randomized controlled trials (RCTs) have examined the benefits of preoperative beta-blocker use in CABG. In contrast, some retrospective cohort studies showed that the use of preoperative beta-blockers did not affect either short-term mortality or morbidity in patients undergoing $\mathrm{CABG}{ }^{15,16}$

To date, no meta-analysis has investigated the clinical outcomes of preoperative beta-blocker use in CABG. Moreover, the majority of clinical trials have targeted beta-blocker use after CABG rather than their preoperative use. ${ }^{17,18}$ Although recent guidelines have downgraded the recommendations for initiation of beta-blockers in high-risk patients with coronary disease, the supporting evidence is inadequate. Given the debatable efficacy of preoperative blockers, we conducted a systematic review and meta-analysis of all published studies comparing a preoperative beta-blocker group with a non-beta-blocker group, aiming to investigate the short-term effects of preoperative beta-blocker use for patients undergoing isolated CABG.

\section{MATERIALS AND METHODS \\ Searching Platforms and Methods}

This systematic review and meta-analysis was reported according to the guidelines of the Meta-analysis Of Observational Studies in Epidemiology (MOOSE) group ${ }^{19}$ and the Preferred Reporting Items for Systematic Reviews and Meta-Analyses. ${ }^{20}$ We searched PubMed, Embase, and the Cochrane Library for English articles published from inception to August 16,2016 , using the following search terms: "beta-blocker" or " $\beta$-blocker" and "coronary artery bypass grafting." We also searched for ongoing or completed studies on the same topic on ClinicalTrials.gov and reviewed references of the identified studies to identify further relevant studies.

\section{Literature Selection Criteria}

The population, intervention, comparator, outcome, and study design approach was used to establish the selection criteria for our meta-analysis. Studies meeting the following criteria were included

1. Population: The population of interest was patients undergoing isolated CABG. Studies targeting patients undergoing CABG with other cardiac operations or other cardiac procedures (heart valve repair or replacement, aneurysm repair, or percutaneous coronary intervention) were excluded. When the same population was reported in the several articles, only the largest study was considered for inclusion.

2. Intervention: Preoperative beta-blocker use. Studies that focused on the combination therapy of beta-blockers and other drugs were not included in the meta-analysis.

3. Comparator: The beta-blocker group versus the non-beta-blocker group

4. Outcome: Operative mortality, myocardial infarction (MI), stroke, atrial fibrillation (AF), prolonged ventilation, renal failure, reoperation, and sternal wound infection.

5. Study Design: Observational epidemiological studies (cohort study).

\section{Data Collection and Quality Assessment}

Two authors (L.W. and H.W.) independently assessed the selected literature and singled out all observational studies meeting the inclusion criteria. For cases with missing information or when clarification was needed, we contacted the original authors to obtain additional information. Disagreements within the team were resolved through discussion. The 2 authors independently reviewed all eligible studies and extracted the following information: first author and year of publication, setting, design, study size, inclusion and exclusion criteria, basic patient characteristics, intervention, and outcomes (as mentioned previously). The Newcastle Ottawa Scale was used to assess the methodologic quality of observational studies. ${ }^{21}$ A greater overall score indicated a lower risk of bias; a score of 5 or less (of 9) suggested a high risk of bias. Risk of bias also was evaluated independently by 2 authors.

\section{Outcomes and Definitions}

The primary outcome was operative mortality, defined as death within 30 days of surgery. The secondary outcomes were the following major postoperative, in-hospital complications: $\mathrm{MI}$, stroke, AF, prolonged ventilation, renal failure, reoperation, and sternal wound infection. Prolonged ventilation included any pulmonary ventilator use for more than 24 hours. Postoperative renal failure was defined as creatinine level increases to more than twice the preoperative value, an absolute value $>2.0 \mathrm{mg} / \mathrm{dL}$, or new requirement for dialysis. Any reoperation included reoperation for bleeding, graft occlusion, valvular dysfunction, or other cardiac reasons.

\section{Statistical Analyses}

This study used Stata/SE12.0 (StataCorp, College Station, Tex) for data analysis. The results were expressed as odds ratios (OR) with a $95 \%$ confidence interval $(95 \% \mathrm{CI})$. Statistical heterogeneity was evaluated with the Q statistic $(P<.1$ was considered indicative of statistically significant heterogeneity) and $\mathrm{I}^{2}$ test $\left(\mathrm{I}^{2}>50 \%\right.$ denoted a high degree of statistically significant heterogeneity). ${ }^{22}$ The random-effects model was used for all comparisons due to the wide range of clinical and methodological variability across the studies. The pooled OR estimates were calculated with the Mantel-Haenszel method. Pooled analyses of unadjusted data, risk-adjusted (RA) data, and data from propensity score analysis (PSA) were all performed to identify the effect of preoperative risks on outcomes. Pooled analysis of PSA data was the primary analysis. Subgroup analysis of propensity-matched data were performed to control bias and to test the sensitivity of the primary result. Publication biases were evaluated with the Begg and Egger tests. ${ }^{23,24}$ Furthermore, one-way 


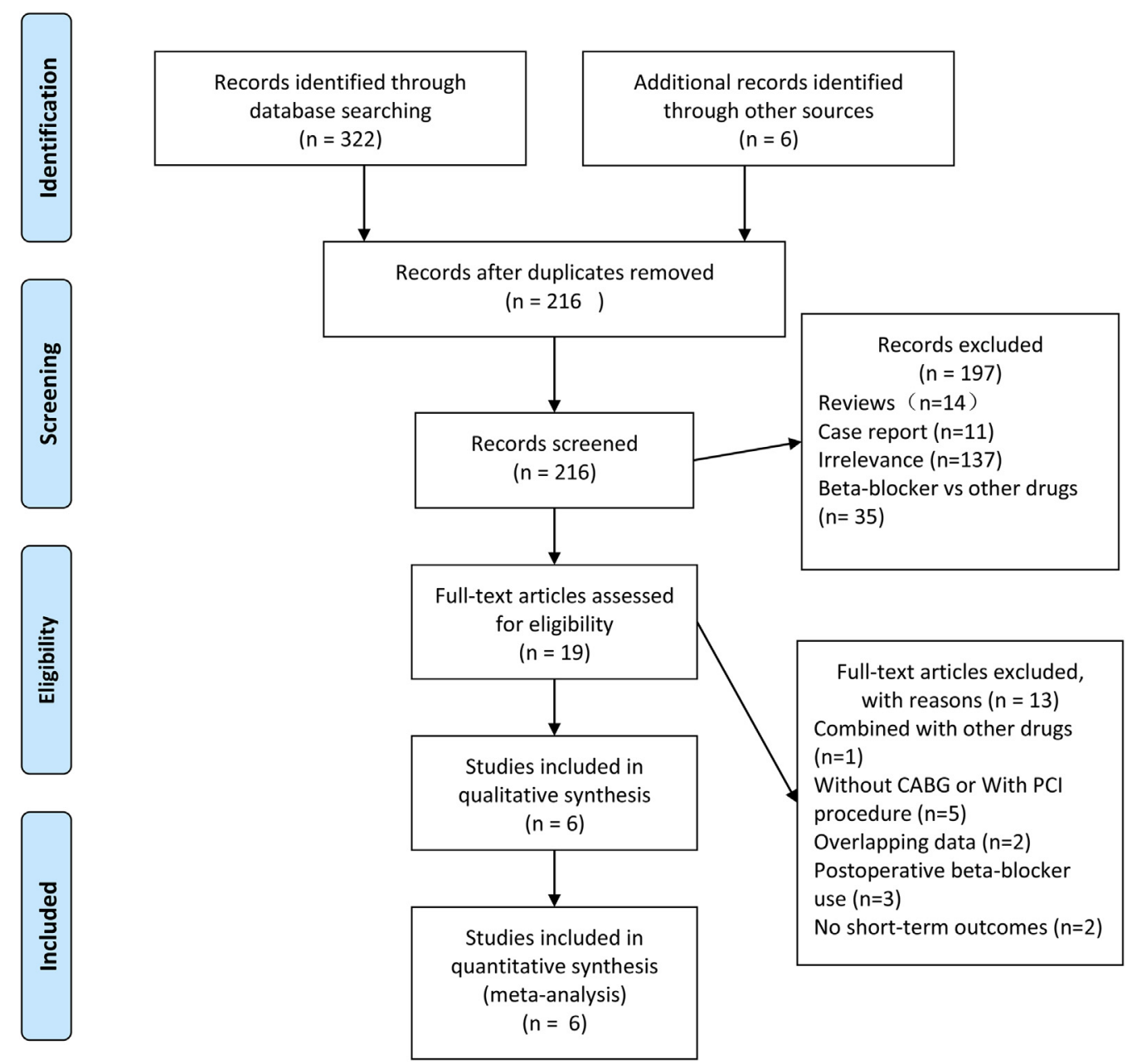

FIGURE 1. Flow diagram for selection of studies. $C A B G$, Coronary artery bypass grafting; $P C I$, percutaneous coronary intervention.

sensitivity analysis was performed to examine the influence of individual studies on the summary effect estimate, in which the meta-analysis estimates are computed omitting one study at a time. $P$ values less than .05 were considered to be statistically significant.

\section{RESULTS}

\section{Search Results and Study Characteristics}

Three hundred and twenty-eight records were identified through a computerized literature search, among which 112 were duplicates and 197 were excluded after an initial review of titles and abstracts. The remaining 19 publications were reviewed in full-text and assessed against inclusion criteria. Finally, 6 studies were included in our study. ${ }^{15,16,25-28}$ The search and selection process is depicted in a Preferred Reporting Items for Systematic Reviews and MetaAnalyses flow diagram (Figure 1). Descriptions of included studies are presented in Table 1. This study included $1,231,850$ patients $(836,687$ in the beta-blocker group and 395,163 in the non-beta-blocker group). All of the included studies were observational studies. Five of the six included studies were multicenter studies. All of the studies investigated operative mortality, incidence of prolonged ventilation, renal failure, and stroke; 3 reported incidence of MI, 4 reported incidence of $\mathrm{AF}^{15,16,26,27} ; 5$ reported incidence of reoperation ${ }^{15,16,25-27}$; and 5 reported incidence of sternal wound infection. ${ }^{15,16,25-27}$ In addition, 5 of the 6 included studies presented major RA outcomes ${ }^{15,16,25,27,28}$; and 5 reported postoperative PSA data. ${ }^{15,25-28}$ Of this last group, 4 performed propensity score matching, ${ }^{15,25,27,28}$ and the other used propensity score covariate adjustment. ${ }^{26}$ All of the variables used for the PSA are presented in Table E1, which were similar among the studies. Inclusion and exclusion criteria were similar among the included studies. In addition, almost $90 \%$ of patients were derived from 2 studies. $^{25,27}$

The baseline characteristics of the included observational studies are summarized in Table 2. Patient characteristics were similar between the beta-blocker group and the non-beta-blocker group. The mean age was 65 years for the included studies. Seventy-three percent were male. Most of the patients suffered from hypertension, previous MI, and 3-vessel disease. 
TABLE 1. Description of included studies

\begin{tabular}{|c|c|c|c|c|c|c|}
\hline Author, year & Setting & Design & $\begin{array}{c}\text { Patient } \\
\text { beta-blocker/ } \\
\text { control, } \\
\text { patients, } \mathbf{n}\end{array}$ & $\begin{array}{c}\text { Time of } \\
\text { perioperative } \\
\text { beta-blocker use }\end{array}$ & Inclusion & Exclusion \\
\hline $\begin{array}{l}\text { Ferguson and } \\
\text { colleagues, } \\
2002\end{array}$ & $\begin{array}{l}\text { Multicenter } \\
\text { (USA and } \\
\text { Canada) }\end{array}$ & $\begin{array}{l}\text { OS with a PSA } \\
\text { (PS matching) }\end{array}$ & $343,912 / 285,965$ & Preoperatively & $\begin{array}{l}\text { Patients in the NCD } \\
\text { who underwent CABG } \\
\text { between } 1996 \text { and } 1999\end{array}$ & $\begin{array}{l}\text { Patients underwent concomitant } \\
\text { valve surgery or other } \\
\text { cardiac procedures, or whose } \\
\text { information on beta-blocker } \\
\text { use was not available. }\end{array}$ \\
\hline $\begin{array}{l}\text { Srinivasan and } \\
\text { colleagues, } \\
2003\end{array}$ & $\begin{array}{l}\text { Single center } \\
\text { (UK) }\end{array}$ & $\begin{array}{l}\text { OS with a PSA } \\
\text { (PS covariate } \\
\text { adjustment) }\end{array}$ & $2836 / 1545$ & Preoperatively & $\begin{array}{l}\text { Patients undergoing } \\
\text { CABG performed } \\
\text { on cardiopulmonary } \\
\text { bypass }\end{array}$ & $\begin{array}{l}\text { Patients undergoing CABG that } \\
\text { was incidental to heart valve } \\
\text { repair or replacement, } \\
\text { resection of a ventricular } \\
\text { aneurysm or other surgical } \\
\text { procedure, or who received } \\
\text { off-pump CABG. }\end{array}$ \\
\hline $\begin{array}{l}\text { Brinkman and } \\
\text { colleagues, }{ }^{15} \\
2011\end{array}$ & $\begin{array}{l}\text { Multicenter } \\
\text { (USA) }\end{array}$ & $\begin{array}{l}\text { OS with a PSA } \\
\text { (PS matching) }\end{array}$ & $7967 / 4888$ & Preoperatively & $\begin{array}{l}\text { STS-certified database } \\
\text { undergoing isolated } \\
\text { CABG from } 2000 \\
\text { to } 2008 .\end{array}$ & None \\
\hline $\begin{array}{l}\text { LaPar and } \\
\text { colleagues, }{ }^{16} \\
2013\end{array}$ & $\begin{array}{l}\text { Multicenter } \\
\text { (USA) }\end{array}$ & $\begin{array}{l}\text { OS (hierarchal } \\
\text { logistic } \\
\text { regression) }\end{array}$ & $35,100 / 8647$ & Preoperatively & $\begin{array}{l}\text { Patients undergoing } \\
\text { primary, isolated } \\
\text { CABG operations. }\end{array}$ & None \\
\hline $\begin{array}{l}\text { Brinkman and } \\
\text { colleagues, }^{27} \\
2014\end{array}$ & $\begin{array}{l}\text { Multicenter } \\
\text { (USA and } \\
\text { Canada) }\end{array}$ & $\begin{array}{l}\text { OS with a PSA } \\
\text { (PS matching) }\end{array}$ & $436,476 / 69,634$ & $\begin{array}{l}\text { Within } 24 \mathrm{~h} \\
\text { preceding } \\
\text { surgery }\end{array}$ & $\begin{array}{l}\text { Patients } 18 \text { y and older } \\
\text { who underwent } \\
\text { nonemergency } \\
\text { isolated CABG } \\
\text { surgery at STS-NCD- } \\
\text { participating } \\
\text { hospitals from } \\
\text { January 1, 2008, } \\
\text { through December } \\
\text { 31, 2012. }\end{array}$ & $\begin{array}{l}\text { Patients with previous MI } \\
\text { within } 21 \mathrm{~d} \text {, with a } \\
\text { documented contraindication } \\
\text { to beta-blocker therapy, or } \\
\text { with high-risk presenting } \\
\text { symptoms (shock, previous } \\
\text { PCI within } 6 \mathrm{~h} \text {, or } \\
\text { preoperative IABP or } \\
\text { inotropes). }\end{array}$ \\
\hline $\begin{array}{l}\text { Kohsaka and } \\
\text { colleagues, } \\
2016\end{array}$ & $\begin{array}{l}\text { Multicenter } \\
\quad \text { (Japan) }\end{array}$ & $\begin{array}{l}\text { OS with a PSA } \\
\text { (PS matching) }\end{array}$ & $10,496 / 24,484$ & $\begin{array}{l}\text { During the } 24-\mathrm{h} \\
\text { period before } \\
\text { cardiac surgery. }\end{array}$ & $\begin{array}{c}\text { Patients underwent } \\
\text { isolated CABG. }\end{array}$ & $\begin{array}{l}\text { Patients underwent concomitant } \\
\text { valve surgery or other cardiac } \\
\text { procedures. }\end{array}$ \\
\hline
\end{tabular}

$O S$, Observational study; $P S A$, propensity score analysis; $P S$, propensity score; $N C D$, National Adult Cardiac database; $C A B G$, coronary artery bypass grafting; $S T S$, Society of Thoracic Surgeons; $M I$, myocardial infraction; $P C I$, percutaneous coronary intervention; IABP, intra-aortic balloon pump.

\section{Quality Assessment}

The quality assessment of 6 observational studies is shown in Table 3. According to the Newcastle-Ottawa Scale to assess the risk of bias in the observational studies, 6 observational studies scored between 6 and 8, indicating high methodologic quality.

\section{Primary Outcome: Operative Mortality}

All studies reported on operative mortality. The pooled results from the random effect models for operative mortality are shown in Table 4 . A total of $1,231,850$ patients were included in the analysis. Of the 27,444 deaths among $1,231,850$ patients undergoing CABG, 15,882 deaths occurred in 836,687 patients $(1.9 \%)$ of the beta-blocker group, whereas 11,562 deaths occurred in 395,163 patients
$(2.9 \%)$ of the control group. Overall analysis of the 6 observational studies showed that the preoperative use of beta-blockers significantly reduced operative mortality in patients undergoing isolated CABG compared with the non-beta-blocker group (OR $0.82 ; 95 \%$ CI $0.71-0.95$; $P=.007)$, with significant heterogeneity among studies $\left(\mathrm{I}^{2}=90.4 \%, P=.000\right)$. Pooling the RA OR from 5 studies consistently showed a significant reduction in operative mortality in patients receiving beta-blockers before CABG compared with the control group (OR, 0.95; 95\% CI, $0.92-0.97 ; \quad P=.000)$, without heterogeneity $\left(\mathrm{I}^{2}=0.0 \%, P=.763\right)$.

However, a pooled analysis of postoperative PSA data generated a statistically nonsignificant result favoring preoperative beta-blocker use (OR, 0.97; 95\% CI, 0.94$1.00 ; P=.088$; Figure 2 ), and no significant heterogeneity 
TABLE 2. Baseline characteristics of included studies

\begin{tabular}{|c|c|c|c|c|c|c|}
\hline Variable & $\begin{array}{c}\text { Ferguson and } \\
\text { colleagues, }^{25} \\
2002 \\
\end{array}$ & $\begin{array}{c}\text { Srinivasan and } \\
\text { colleagues, }^{26} \\
2003 \\
\end{array}$ & $\begin{array}{c}\text { Brinkman and } \\
\text { colleagues, }^{15} \\
2011 \\
\end{array}$ & $\begin{array}{c}\text { LaPar and } \\
\text { colleagues, }^{16} \\
2013\end{array}$ & $\begin{array}{c}\text { Brinkman and } \\
\text { colleagues, }^{27} \\
2014 \\
\end{array}$ & $\begin{array}{c}\text { Kohsaka and } \\
\text { colleagues }^{28} \\
2016\end{array}$ \\
\hline \multicolumn{7}{|c|}{ No. of propensity-matched patients } \\
\hline Preop.b-b & 230,053 & & 4474 & & 69,271 & 9619 \\
\hline No preop.b-b & 230,053 & & 4474 & & 69,271 & 9619 \\
\hline \multicolumn{7}{|l|}{ Mean age, $y$} \\
\hline Preop.b-b & 64 & 63.7 & 63.2 & 63.8 & 64.9 & 68.0 \\
\hline No preop.b-b & 65 & 65.3 & 64.6 & 64.7 & 65.7 & 68.7 \\
\hline \multicolumn{7}{|l|}{ Males, \% } \\
\hline Preop.b-b & 70.9 & 81.0 & 73.8 & 73.3 & 73.7 & 77.8 \\
\hline No preop.b-b & 71.0 & 80.5 & 75.1 & 74.9 & 75.7 & 78 \\
\hline \multicolumn{7}{|c|}{ Diabetes mellitus, \% } \\
\hline Preop.b-b & 30.2 & 13.9 & 33.7 & 38.8 & 42.6 & 52.7 \\
\hline No preop.b-b & 32.7 & 19.9 & 35.9 & 37.5 & 39.5 & 49.8 \\
\hline \multicolumn{7}{|l|}{ Hypertension, \% } \\
\hline Preop.b-b & & 51.6 & 79.3 & 81.2 & 88.7 & 82.4 \\
\hline No preop.b-b & & 48.5 & 72.9 & 73.4 & 81.9 & 73.9 \\
\hline \multicolumn{7}{|l|}{ Previous MI, \% } \\
\hline Preop.b-b & 53.0 & 46.1 & 45.3 & 16.7 & 27.4 & 39.1 \\
\hline No preop.b-b & 44.9 & 47.8 & 33.4 & 4.5 & 18.6 & 35 \\
\hline \multicolumn{7}{|c|}{ Ejection fraction, $\%$} \\
\hline Preop.b-b & 51.0 & & 50.3 & 0.55 & 53.3 & \\
\hline No preop.b-b & 49.9 & & 50.5 & 0.55 & 54.9 & \\
\hline \multicolumn{7}{|c|}{ Three-vessel disease } \\
\hline Preop.b-b & 70.6 & 83.5 & 79.3 & 78.3 & 73.5 & 71.8 \\
\hline No preop.b-b & 69.8 & 84.9 & 78.5 & 76.5 & 71.2 & 68.6 \\
\hline
\end{tabular}

The Srinivasan study used PS covariate adjustment rather than PS matching, and the LaPar study was adjusted using hierarchal logistic regression. Preop.b-b, Preoperative beta-blocker group; no Preop. $b$ - $b$, preoperative non-beta-blocker group; $M I$, myocardial infarction.

was observed $\left(\mathrm{I}^{2}=0.0 \%, P=.888\right)$. When we removed one study that used propensity score covariate adjustment, subgroup analysis of propensity-matched patients $(313,417$ in each group) still generated a statistically nonsignificant benefit for preoperative beta-blocker use (OR, 0.97; 95\% CI, 0.94-1.00; $P=.093$; Figure 2).

\section{Secondary Outcome: Incidence of Major Postoperative Complications}

Pooled outcomes of the incidence of major postoperative complications are presented in Table 4. Incidence of stroke was available in all studies. Preoperative beta-blocker use was associated with a slightly lower incidence of stroke (OR, 0.89; 95\% CI, 0.80-0.99; $P=.039$ ). The random-effects model was applied because heterogeneity was evident among the studies $\left(\mathrm{I}^{2}=73.5 \%, P=.002\right)$. However, there was no significant difference between the 2 groups regarding the incidence of stroke when pooling either the RA outcome (OR, 0.97; 95\% CI, 0.93-01.01; $P=.094)$ or PSA outcome (OR, 0.96; 95\% CI, $0.89-1.04 ; P=.313$ ). Only 4 studies investigated the incidence of AF. Overall analysis of studies revealed that the preoperative use of beta-blockers significantly increased the incidence of $\mathrm{AF}$ (OR, 1.08; 95\% CI, 1.06-1.10; $P=.000)$, without substantial heterogeneity $\left(\mathrm{I}^{2}=0 \%\right.$, $P=.504)$. These findings were consistent with the pooled analysis of either RA outcome or PSA outcome. Reoperation was extracted in 5 studies. The incidence of reoperation in patients receiving preoperative beta-blockers was reduced by $4 \%$ compared with patients who did not receive preoperative beta-blockers (OR, 0.96; $95 \%$ CI, 0.92-1.00; $P=.036$ ). Conversely, pooled analyses of RA outcome or PSA outcome demonstrated no statistically significant difference in the incidence of reoperation between the 2 groups.

Moreover, preoperative beta-blocker use did not significantly reduce the incidence of MI (PSA: OR, 1.05; $95 \% \mathrm{CI}, 0.84-1.31, P=.693$ ), the incidence of renal failure (OR, 0.92; 95\% CI, 0.84-1.01; $P=.086$; PSA: OR, 1.00; $95 \%$ CI, $0.95-1.06, P=.989$ ), or the incidence of prolonged ventilation (OR, $0.90 ; 95 \% \mathrm{CI}, 0.80-1.01$; $P=.080$; PSA: OR, $1.00 ; 95 \%$ CI, 0.96-1.04; $P=.967)$. Similarly, the incidence of sternal wound infection did not markedly decrease after preoperative beta-blocker use (OR, 0.93; 95\% CI, 0.86-1.01, $P=.098$; PSA: OR, 0.95; $95 \%$ CI, 0.86-1.05, $P=.285$ ). 
TABLE 3. Quality assessment of observational studies

\begin{tabular}{|c|c|c|c|c|c|c|c|c|c|}
\hline \multirow[b]{2}{*}{ Study } & \multicolumn{4}{|c|}{ Selection } & \multirow[b]{2}{*}{ Comparability } & \multicolumn{4}{|c|}{ Outcome } \\
\hline & $\begin{array}{c}\text { Exposed } \\
\text { cohort }\end{array}$ & $\begin{array}{c}\text { Nonexposed } \\
\text { cohort }\end{array}$ & $\begin{array}{c}\text { Ascertainment } \\
\text { of exposure }\end{array}$ & $\begin{array}{l}\text { Outcome } \\
\text { of Interest }\end{array}$ & & $\begin{array}{l}\text { Assessment } \\
\text { of outcome }\end{array}$ & $\begin{array}{l}\text { Length of } \\
\text { follow-up }\end{array}$ & $\begin{array}{l}\text { Adequacy } \\
\text { follow-up }\end{array}$ & $\begin{array}{l}\text { Total } \\
\text { score }\end{array}$ \\
\hline $\begin{array}{l}\text { Ferguson and } \\
\text { colleagues, }^{25} \\
2002\end{array}$ & * & $*$ & * & $*$ & $*$ & $*$ & $*$ & $*$ & 8 \\
\hline $\begin{array}{l}\text { Srinivasan and } \\
\text { colleagues, }^{26} \\
2003\end{array}$ & * & $*$ & * & $*$ & $*$ & - & $*$ & - & 6 \\
\hline $\begin{array}{l}\text { Brinkman and } \\
\text { colleagues, }^{15} \\
2011\end{array}$ & $*$ & $*$ & $*$ & $*$ & $*$ & $*$ & $*$ & $*$ & 8 \\
\hline $\begin{array}{l}\text { LaPar and } \\
\text { colleagues, }{ }^{16} \\
2013\end{array}$ & * & $*$ & * & $*$ & $*$ & $*$ & $*$ & $*$ & 8 \\
\hline $\begin{array}{l}\text { Brinkman and } \\
\text { colleagues, }^{27} \\
2014\end{array}$ & * & * & * & * & $*$ & $*$ & $*$ & * & 8 \\
\hline $\begin{array}{l}\text { Kohsaka and } \\
\text { colleagues, }^{28} \\
2016\end{array}$ & * & $*$ & * & * & * & * & * & * & 8 \\
\hline
\end{tabular}

Risk of bias was assessed with the Newcastle-Ottawa Scale. A greater overall score indicated a lower risk of bias; a score of 5 or less (of 9) suggested a high risk of bias.

\section{Publication Basis and Sensitivity Analyses}

The results of publication bias tests are presented in Table 4. All of the $P$ values for the Begg and Egger tests were greater than .05 , suggesting a low probability of publication bias. We also performed a one-way sensitivity analysis of PSA outcomes to estimate the effect of each study on operative mortality. In this analysis, omission of each study did not make a significant difference (Figure 3), confirming the stability of our results.

TABLE 4. Meta-analysis for all outcomes and publication bias

\begin{tabular}{|c|c|c|c|c|c|c|}
\hline Outcomes & OR $(95 \%$ CI $)$ & $\mathbf{z}$ & $P$ value & $\mathbf{I}^{2}(\%)$ & Begg's $P$ & Egger's $P$ \\
\hline Operative mortality & $0.82(0.71-0.95)$ & 2.70 & .007 & 90.4 & 1.000 & .934 \\
\hline RA & $0.95(0.92-0.97)$ & 3.78 & .000 & 0.0 & .806 & .239 \\
\hline PSA & $0.97(0.94-1.00)$ & 1.71 & .088 & 0.0 & 1.000 & .542 \\
\hline Stroke & $0.89(0.80-0.99)$ & 2.07 & .038 & 73.4 & .707 & .360 \\
\hline RA & $0.97(0.93-1.01)$ & 1.68 & .094 & 0.0 & .734 & .313 \\
\hline PSA & $0.96(0.89-1.04)$ & 1.01 & .313 & 33.2 & .221 & .225 \\
\hline Atrial arrhythmia & $1.08(1.06-1.10)$ & 7.97 & .000 & 0.0 & 1.000 & .755 \\
\hline RA & $1.10(1.06-1.14)$ & 4.87 & .000 & 32.9 & 1.000 & \\
\hline PSA & $1.12(1.02-1.22)$ & 2.50 & .012 & 42.9 & 1.000 & \\
\hline Prolonged ventilation & $0.90(0.80-1.01)$ & 1.75 & .08 & 96.4 & 1.000 & .870 \\
\hline RA & $0.97(0.94-1.01)$ & 1.65 & .099 & 45.8 & 1.000 & .256 \\
\hline PSA & $1.00(0.96-1.04)$ & 0.04 & .967 & 35.7 & 1.000 & .291 \\
\hline Renal failure & $0.92(0.84-1.01)$ & 1.72 & .086 & 85.2 & 1.000 & .671 \\
\hline RA & $1.00(0.91-1.10)$ & 0.02 & .988 & 84.9 & .734 & .173 \\
\hline PSA & $1.00(0.95-1.06)$ & 0.01 & .989 & 40.0 & 1.000 & .332 \\
\hline Reoperation & $0.96(0.92-1.00)$ & 2.10 & .036 & 35.2 & .462 & .328 \\
\hline RA & $0.99(0.97-1.00)$ & 1.60 & .110 & 0.0 & 1.000 & .568 \\
\hline PSA & $1.00(0.98-1.03)$ & 0.38 & .705 & 0.0 & 1.000 & .744 \\
\hline Sternal wound infection & $0.93(0.86-1.01)$ & 1.65 & .098 & 22.3 & .462 & .204 \\
\hline RA & $0.86(0.72-1.03)$ & 1.65 & .098 & 71.2 & 1.000 & .227 \\
\hline PSA & $0.95(0.86-1.05)$ & 1.07 & .285 & 22.2 & .806 & .589 \\
\hline Myocardial infraction (PSA) & $1.05(0.84-1.31)$ & 0.39 & .693 & 0.0 & & \\
\hline
\end{tabular}

$O R$, Odds ratio; $C I$, confidence interval; $R A$, risk-adjusted; $P S A$, propensity score analysis. 


\section{DISCUSSION}

This study analyzed 6 observational studies to investigate the short-term effects of preoperative beta-blocker use versus non-beta-blocker use for patients undergoing isolated CABG. The current meta-analysis showed that preoperative beta-blocker use did not significantly reduce operative mortality and the incidence of some postoperative complications, such as postoperative MI, stroke, reoperation, renal failure, prolonged ventilation, and sternal wound infection. However, we found that preoperative beta-blocker use significantly increased the incidence of AF.

Beta-blockers have been used routinely as a main therapy for patients with cardiovascular disease over the past 20 years, based on the evidence that beta-blockers can correct the imbalance between oxygen demand and supply. ${ }^{29}$ Recent guidelines suggest that preoperative beta-blockers may be beneficial for patients undergoing CABG without contraindications. ${ }^{30,31}$ However, there always has been controversy regarding whether the potential benefits of preoperative beta-blockers use outweigh its risks for patients undergoing CABG.

Previously, many meta-analyses have focused on the comparison of beta-blocker use and non-beta-blocker use. Bangalore and colleagues ${ }^{32}$ included 33 RCTs with 12,306 patients undergoing noncardiac surgery and found that beta-blockers did not significantly reduce the risk of all cause-mortality, cardiovascular mortality or heart failure, but it reduced the incidence of non-fatal MI by
$35 \%$ and increased the incidence of nonfatal stroke by $101 \%$. Wan and colleagues ${ }^{33}$ also found no significant difference in the risk of death between patients undergoing CABG who either did or did not receive beta-blockers before surgery. Bangalore and colleagues ${ }^{34}$ conducted a meta-analysis of 6 RCTs including 102,003 patients to evaluate beta-blockers in MI, and they demonstrated that beta-blockers had no mortality benefit but reduced recurrent MI and angina (short term) at the expense of increase in heart failure and cardiogenic shock. These findings may challenge the value of beta-blockers in preventing cardiovascular events. Nevertheless, most previous meta-analyses have not centered on patients undergoing CABG.

To the best of our knowledge, this study is the first systematic review and meta-analysis to target patients undergoing isolated $\mathrm{CABG}$ for comparing the short-term effects of preoperative beta-blocker use with non-beta-blocker use. In the present study, we included 6 observational studies with a total of $1,231,850$ patients and performed pooled analyses of RA and PSA outcomes, which may reduce the risk of patient selection bias. In addition, the results of risk assessment of bias showed that our included studies were at low risk of bias. Hence, the included studies in the present meta-analysis were of satisfactory methodological quality.

It has been demonstrated that beta-blockers are efficient in preventing ventricular arrhythmias and sudden death. ${ }^{35}$ Moreover, beta-blockers may be associated with a reduction

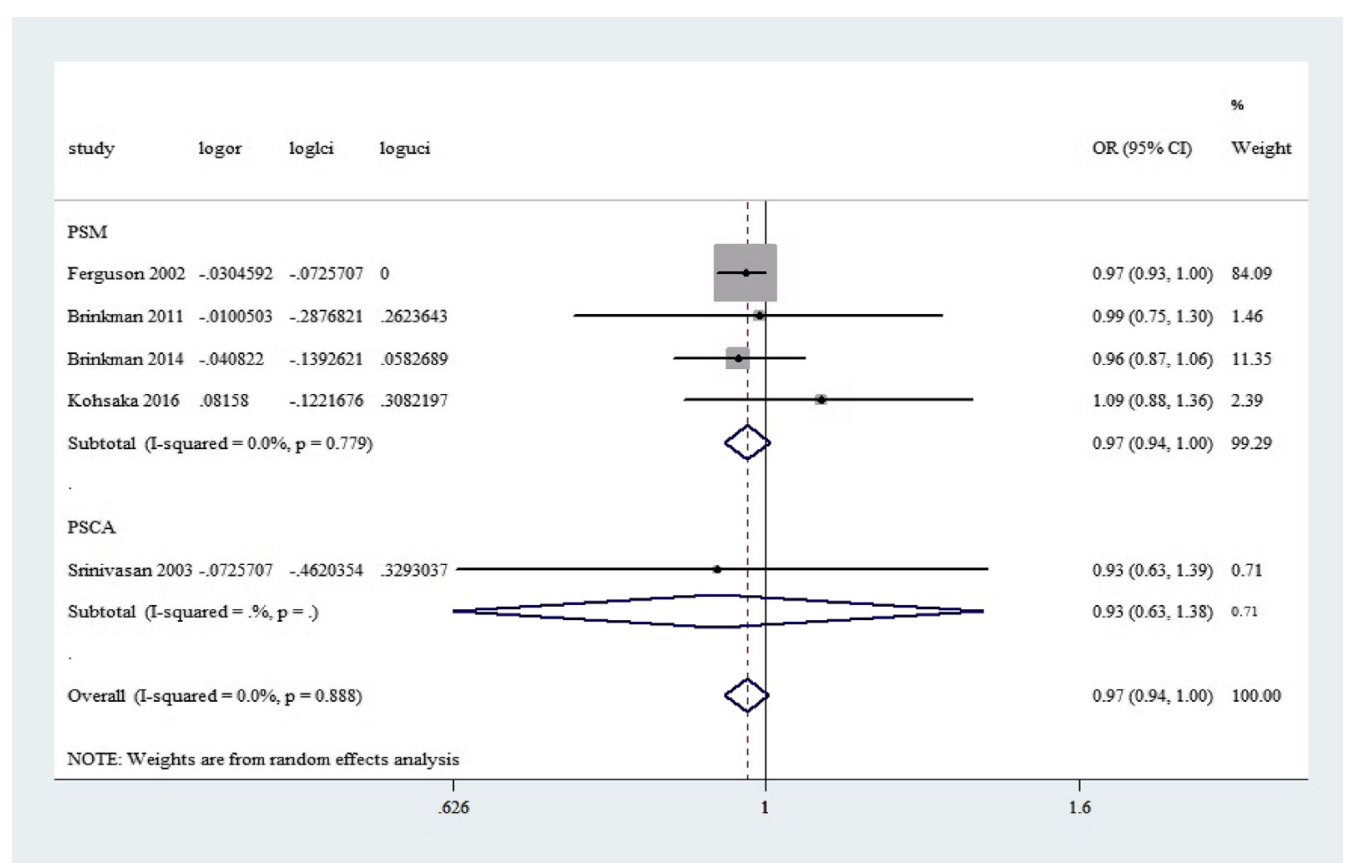

FIGURE 2. Forest plot of operative mortality outcome from propensity score analysis. PSM, Propensity score matching; PSCA, propensity-score covariate adjustment; $O R$, odds ratio; $C I$, confidence interval. 


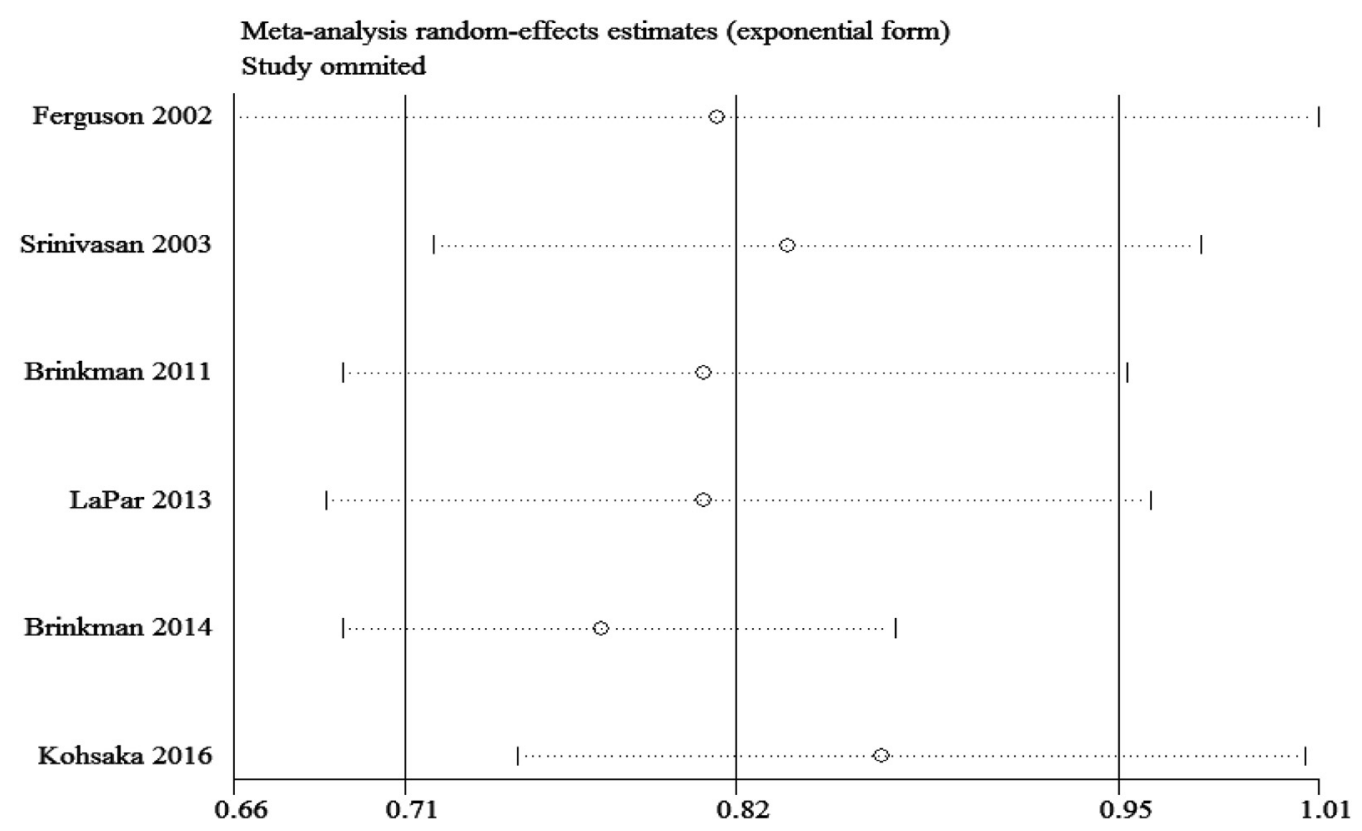

FIGURE 3. One-way sensitivity analysis of operative mortality outcome from propensity score analysis.

in the incidence of MI because their negative inotropic effects may reduce myocardial contractility and consequently result in a decline in oxygen demand. ${ }^{34}$ Nonetheless, negative inotropic effects also could lead to heart failure and cardiogenic shock. In this current meta-analysis, we found that preoperative beta-blocker use did not significantly reduce the incidence of MI. Ventricular arrhythmias, sudden death, heart failure, and MI are the major causes of operative mortality. Among the included studies, outcomes of ventricular arrhythmias, sudden death, or cardiogenic shock were not reported. In the present meta-analysis, no significant improvement in short-term survival was observed in the beta-blocker group compared with the control group. The benefits of preoperative beta-blocker use may be counteracted by the risk of heart failure. Furthermore, contemporary medical and device therapies are reducing the impact of beta-blockers, due to their efficacy in reducing the risk of arrhythmic deaths and cardiogenic shock.

Beta-blocker use was found to be associated with the increased risk of nonfatal stroke in the previous meta-analyses and RCTs. ${ }^{32,36,37}$ The results from the Perioperative Ischemic Evaluation (POISE) trial suggested that beta-blockers could increase the risk of stroke due to hypotension. ${ }^{36}$ Conversely, the overall results showed that beta-blockers had no effect on stroke in the real word. Similarly, these studies showed that beta-blockers also could lead to kidney injury due to hypotension, whereas this phenomenon was not observed in our studies. In the real word, blood pressure monitoring is performed routinely, and appropriate and stable blood pressure should be obtained during the perioperative period, which may account for our findings.

Postoperative AF is a common complication of cardiovascular surgery, and it occurs in more than $20 \%$ of patients undergoing CABG. ${ }^{38}$ Postoperative $\mathrm{AF}$ has a marked association with the prolonged length of hospital stay and increased hospital charges. In addition, the incidence of major adverse cardiovascular events is always greater in patients with postoperative $\mathrm{AF}^{39}$ Beta-blockers consistently have been shown to prevent AF after surgery by heart rhythm control. However, this study observed that preoperative beta-blocker therapy significantly increased the incidence of postoperative AF. The pooled odds ratio was 1.12 , indicating a small magnitude of difference between 2 groups regarding development of AF. Among the included studies, information of the use of amiodarone was absent. Amiodarone is often the preferred prophylactic antiarrhythmic agent in the real world, ${ }^{40}$ and the use of this drug in the non-beta-blocker group might have reduced postoperative $\mathrm{AF}$, which might explain the relatively increased rate of postoperative $\mathrm{AF}$ in the beta-blocker group.

According to several reports, ${ }^{41,42}$ beta 2 -blockade agent in noncardioselective beta-blockers may increase airflow obstruction in susceptible patients, possibly through unopposed parasympathetic bronchoconstriction. In the current meta-analysis, we found no difference in prolonged ventilation between the beta-blocker group and the control group. This result suggested that low-dose initiation of beta-blockers also might be recommended to patients with mild and fixed airflow obstruction. However, pulmonary 
function should be carefully evaluated before prescribing beta-agonists to patients.

Preoperative risks to patients could be an important variable in comparing the morbidity and mortality between 2 groups. In the present study, the pooled analyses of either unadjusted outcomes or RA outcomes showed a slight reduction in operative mortality, whereas an insignificant difference in mortality rates was observed in pooling postoperative PSA data or propensity-matched data. The strength of the evidence from PSA was robust because comparability between the 2 groups was well-established, and selective bias was reduced. Two included studies performed subgroup analyses in patients with left ventricular dysfunction. One found that preoperative beta-blocker therapy was associated with a trend toward a greater mortality rate among patients with a left ventricular ejection fraction of less than $30 \%$, whereas the other showed no association between the beta-blocker use and outcome. Almost $90 \%$ of patients were derived from 2 studies, and the results seemed to depend on the data of the 2 studies. However, we also performed a one-way sensitivity analysis of PSA outcomes to estimate the effect of each study on operative mortality. In this analysis, omission of each study did not make a significant difference, confirming the stability of our results.

\section{Limitations}

Nevertheless, this study has several limitations. First, only 6 studies were included in this meta-analysis, and all eligible studies were observational studies that lacked random allocation of intervention, which may have resulted in a greater risk of selection bias. Although we also used the data from PSA, the risk of bias could not be excluded completely, because all methods to control for confounding are imperfect. Despite statistical analysis leading to an evident result, this result comes from studies of low scientific weight in terms of level of evidence; thus, the real impact of preoperative beta-blockers on CABG-outcome has not been be defined to date and certainly deserves RCTs. Second, the dose and type of beta-blockers were unknown in all included studies. Discontinuation of preoperative beta-blockade also was unreported. In addition, the timing of taking beta-blockers was different among the studies. These factors might have affected the pooled results. Finally, most studies did not have classification of perioperative risk (low risk and high risk). This classification might have been useful in evaluating the value of beta-blockers due to the controversial outcomes in patients with high-risk. A standardized risk assessment is necessary for future studies.

In conclusion, our study suggests that the use of perioperative beta-blockers did not reduce either operative mortality or the incidence of postoperative complications in patients undergoing CABG. However, the value of beta-blockers could not be determined by current outcomes because short-term CABG mortality rates, which have decreased to approximately $1 \%$, may no longer be a sufficiently sensitive outcome. We should pay more attention to assess the long-term benefit of beta-blockers. Recently, it was reported that the consistent use of beta-blockers was associated with a lower risk of both long-term mortality and adverse cardiovascular events in patients undergoing CABG. ${ }^{17}$ Hence, RCTs investigating the long-term effects of beta-blocker therapy are still required to confirm their potential benefits for patients undergoing $\mathrm{CABG}$.

\section{Conflicts of Interest Statement}

Authors have nothing to disclose with regard to commercial support.

\section{References}

1. Brown RA, Shantsila E, Varma C, Lip GY. Epidemiology and pathogenesis of diffuse obstructive coronary artery disease: the role of arterial stiffness, shear stress, monocyte subsets and circulating microparticles. Ann Med. 2016;48: 444-55.

2. Sabik JF III. Why coronary artery bypass grafting remains the standard of care for patients with complex, multivessel coronary artery disease. J Thorac Cardiovasc Surg. 2016;152:1227-8.

3. Zheng Z, Zhang H, Xu B. Updated evidence for left main coronary artery disease: practice versus the consensus. J Thorac Cardiovasc Surg. 2017;153:312-3.

4. Locker C, Schaff HV, Daly RC, Dearani JA, Bell MR, Frye RL, et al. Multiple arterial grafts improve survival with coronary artery bypass graft surgery versus conventional coronary artery bypass grafting compared with percutaneous coronary interventions. J Thorac Cardiovasc Surg. 2016;152:369-79.e4.

5. Kim LK, Looser P, Swaminathan RV, Minutello RM, Wong SC, Girardi L, et al. Outcomes in patients undergoing coronary artery bypass graft surgery in the United States based on hospital volume, 2007 to 2011. J Thorac Cardiovasc Surg. 2016;151:1686-92.

6. Fuster V, Badimon L, Badimon JJ, Chesebro JH. The pathogenesis of coronary artery disease and the acute coronary syndromes (2). N Engl J Med. 1992;326: 310-8.

7. Poldermans D, Boersma E. Beta-blocker therapy in noncardiac surgery. $N$ Engl J Med. 2005;353:412-4.

8. Lindenauer PK, Pekow P, Wang K, Mamidi DK, Gutierrez B, Benjamin EM Perioperative beta-blocker therapy and mortality after major noncardiac surgery. N Engl J Med. 2005;353:349-61.

9. Viljoen JF, Estafanous FG, Kellner GA. Propranolol and cardiac surgery. J Thorac Cardiovasc Surg. 1972;64:826-30.

10. Mangano DT, Layug EL, Wallace A, Tateo I. Effect of atenolol on mortality and cardiovascular morbidity after noncardiac surgery. Multicenter Study of Perioperative Ischemia Research Group. N Engl J Med. 1996;335:1713-20.

11. Zaugg M, Tagliente T, Lucchinetti E, Jacobs E, Krol M, Bodian C, et al. Beneficial effects from beta-adrenergic blockade in elderly patients undergoing noncardiac surgery. Anesthesiology. 1999;91:1674-86.

12. Sardana M, Syed AA, Hashmath Z, Phan TS, Koppula MR, Kewan U, et al. Beta-blocker use is associated with impaired left atrial function in hypertension. J Am Heart Assoc. 2017;6.

13. Ten Broecke PW, De Hert SG, Mertens E, Adriaensen HF. Effect of preoperative beta-blockade on perioperative mortality in coronary surgery. $\mathrm{Br} J$ Anaesth. 2003;90:27-31.

14. O'Brien SM, Shahian DM, Delong ER, Normand SL, Edwards FH, Ferraris VA, et al. Quality measurement in adult cardiac surgery: part 2-Statistical considerations in composite measure scoring and provider rating. Ann Thorac Surg. 2007;83:S13-26.

15. Brinkman WT, Herbert MA, Prince SL, Magee MJ, Dewey TM, Smith RL, et al Preoperative beta-blocker usage: is it really worthy of being a quality indicator. Ann Thorac Surg. 2011;92:788-95; discussion 795-6. 
16. LaPar DJ, Crosby IK, Kron IL, Kern JA, Fonner E Jr, Rich JB, et al. Preoperative beta-blocker use should not be a quality metric for coronary artery bypass grafting. Ann Thorac Surg. 2013;96:1539-44; discussion 1544-45.

17. Zhang H, Yuan X, Zhang H, Chen S, Zhao Y, Hua K, et al. Efficacy of long-term beta-blocker therapy for secondary prevention of long-term outcomes after coronary artery bypass grafting surgery. Circulation. 2015;131:2194-201.

18. Effect of metoprolol on death and cardiac events during a 2-year period after coronary artery bypass grafting. The MACB Study Group. Eur Heart J. 1995; 16:1825-32.

19. Stroup DF, Berlin JA, Morton SC, Olkin I, Williamson GD, Rennie D, et al, Meta-analysis of observational studies in epidemiology: a proposal for reporting. Meta-analysis Of Observational Studies in Epidemiology (MOOSE) group. JAMA. 2000;283:2008-12.

20. Moher D, Liberati A, Tetzlaff J, Altman DG, PRISMA Group. Preferred reporting items for systematic reviews and meta-analyses: the PRISMA statement. BMJ. 2009;339:b2535.

21. Wells G, Shea B, O'Connel D, Peterson J, Welch V, Losos M, et al. The Newcastle-Ottawa Scale (NOS) for assessing the quality of nonrandomised studies in meta-analyses [webpage on the Internet]. Ottawa, ON: Ottawa Hospital Research Institute; 2011. Available at: http://www.ohri.ca/programs/clinical_ epidemiology/oxford.asp. Accessed August 10, 2016.

22. Higgins JP, Thompson SG, Deeks JJ, Altman DG. Measuring inconsistency in meta-analyses. BMJ. 2003;327:557-60.

23. Egger M, Davey Smith G, Schneider M, Minder C. Bias in meta-analysis detected by a simple, graphical test. BMJ. 1997;315:629-34.

24. Begg CB, Mazumdar M. Operating characteristics of a rank correlation test for publication bias. Biometrics. 1994;50:1088-101.

25. Ferguson TB Jr, Coombs LP, Peterson ED. Preoperative beta-blocker use and mortality and morbidity following CABG surgery in North America. JAMA. 2002;287:2221-7.

26. Srinivasan AK, Shackcloth MJ, Grayson AD, Fabri BM. Preoperative beta-blocker therapy in coronary artery bypass surgery: a propensity score analysis of outcomes. Interact Cardiovasc Thorac Surg. 2003;2:495-500.

27. Brinkman W, Herbert MA, O'Brien S, Filardo G, Prince S, Dewey T, et al. Preoperative beta-blocker use in coronary artery bypass grafting surgery: national database analysis. JAMA Intern Med. 2014;174:1320-7.

28. Kohsaka S, Miyata H, Motomura N, Imanaka K, Fukuda K, Kyo S, et al. Effects of preoperative beta-blocker use on clinical outcomes after coronary artery bypass grafting: a Report from the Japanese Cardiovascular Surgery Database. Anesthesiology. 2016;124:45-55.

29. Vaishnava P, Eagle KA. Surgery. Beta-blockers—still a trusted ally or time for retirement? Nat Rev Cardiol. 2014;11:502-3.

30. Authors/Task Force members, Windecker S, Kolh P, Alfonso F, Collet JP, Cremer J, Falk V, et al. 2014 ESC/EACTS Guidelines on myocardial revascularization: The Task Force on Myocardial Revascularization of the European Society of Cardiology (ESC) and the European Association for
Cardio-Thoracic Surgery (EACTS)Developed with the special contribution of the European Association of Percutaneous Cardiovascular Interventions (EAPCI). Eur Heart J. 2014;35:2541-619.

31. Hillis LD, Smith PK, Anderson JL, Bittl JA, Bridges CR, Byrne JG, et al. 2011 ACCF/AHA Guideline for Coronary Artery Bypass Graft Surgery: a report of the American College of Cardiology Foundation/American Heart Association Task Force on Practice Guidelines. Circulation. 2011;124:e652-735.

32. Bangalore S, Wetterslev J, Pranesh S, Sawhney S, Gluud C, Messerli FH Perioperative beta blockers in patients having non-cardiac surgery: a meta-analysis. Lancet. 2008;372:1962-76.

33. Wan YD, Zhang SG, Sun TW, Kan QC, Wang LX. The effects of perioperative beta-blockers on mortality in patients undergoing non-cardiac surgery in real world: a meta-analysis of cohort studies. Int J Cardiol. 2014; 176:605-10

34. Bangalore S, Makani H, Radford M, Thakur K, Toklu B, Katz SD, et al. Clinical outcomes with beta-blockers for myocardial infarction: a meta-analysis of randomized trials. Am J Med. 2014;127:939-53.

35. Exner DV, Reiffel JA, Epstein AE, Ledingham R, Reiter MJ, Yao Q, et al. Beta-blocker use and survival in patients with ventricular fibrillation or symptomatic ventricular tachycardia: the Antiarrhythmics Versus Implantable Defibrillators (AVID) trial. J Am Coll Cardiol. 1999;34:325-33.

36. POISE Study Group, Devereaux PJ, Yang H, Yusuf S, Guyatt G, Leslie K, Villar JC, et al. Effects of extended-release metoprolol succinate in patient undergoing non-cardiac surgery (POISE trial): a randomised controlled trial. Lancet. 2008;371:1839-47.

37. Lindholm LH, Carlberg B, Samuelsson O. Should beta blockers remain first choice in the treatment of primary hypertension? A meta-analysis. Lancet. 2005;366:1545-53

38. Aranki SF, Shaw DP, Adams DH, Rizzo RJ, Couper GS, VanderVliet M, et al Predictors of atrial fibrillation after coronary artery surgery. Current trends and impact on hospital resources. Circulation. 1996;94:390-7.

39. Greenberg MD, Katz NM, Iuliano S, Tempesta BJ, Solomon AJ. Atrial pacing for the prevention of atrial fibrillation after cardiovascular surgery. J Am Coll Cardiol. 2000;35:1416-22.

40. Dobrev D, Nattel S. New antiarrhythmic drugs for treatment of atrial fibrillation. Lancet. 2010;375:1212-23.

41. Hawkins NM, Petrie MC, Macdonald MR, Jhund PS, Fabbri LM Wikstrand J, et al. Heart failure and chronic obstructive pulmonary disease the quandary of beta-blockers and beta-agonists. J Am Coll Cardiol. 2011;57:2127-38.

42. Zaid G, Beall GN. Bronchial response to beta-adrenergic blockade. $N$ Engl J Med. 1966;275:580-4.

Key Words: coronary artery bypass grafting, operative mortality, perioperative beta-blocker use 
TABLE E1. Description of variables used in PSA studies

\begin{tabular}{|c|c|c|c|}
\hline Author, year & PSA methodology & Selection bias & Variables \\
\hline $\begin{array}{l}\text { Ferguson and colleagues, } \\
2002\end{array}$ & 1:1 matching method not reported & Lower & $\begin{array}{l}\text { Age, body surface area, sex, NYHA class IV, triple- } \\
\text { vessel disease, left main coronary disease, LVEF, } \\
\text { preoperative IABP, arrhythmia, cerebrovascular } \\
\text { disease, heart failure, MI, cardiogenic shock, } \\
\text { chronic lung disease, dialysis, reoperation, } \\
\text { surgical status. }\end{array}$ \\
\hline $\begin{array}{l}\text { Srinivasan and colleagues, }{ }^{26} \\
2003\end{array}$ & Propensity score covariate adjustment & Lower & $\begin{array}{l}\text { Age, body mass index, sex, NYHA class IV, unstable } \\
\text { angina, previous MI, smoker, diabetes, } \\
\text { hypertension, peripheral vascular disease, } \\
\text { cerebrovascular disease, renal dysfunction, } \\
\text { respiratory disease, heart failure, } \mathrm{LVEF}<30 \%, 3 \text { - } \\
\text { vessel disease, left main stenosis, emergent } \\
\text { procedure. }\end{array}$ \\
\hline $\begin{array}{l}\text { Brinkman and colleagues, }{ }^{15} \\
2011\end{array}$ & $1: 1$ matching method not reported & Lower & $\begin{array}{l}\text { Sex, angina, arrhythmia, heart failure, left main } \\
\text { disease, preoperative IABP, previous PCI, } \\
\text { resuscitation, permanent stroke, cerebrovascular } \\
\text { disease, diabetes, dyslipidemia, hypertension, } \\
\text { peripheral artery disease, renal failure, smoker, } \\
\text { cardiogenic shock, urgent operative status, triple- } \\
\text { vessel disease, NYHA class IV, chronic lung } \\
\text { disease, statins use, age, body surface area, LVEF. }\end{array}$ \\
\hline $\begin{array}{l}\text { Brinkman and colleagues, }{ }^{27} \\
2014\end{array}$ & Greedy 1:1 5-to-1 digit matching & Lower & $\begin{array}{l}\text { Age, body surface area, sex, Hispanic or nonwhite } \\
\text { race, dyslipidemia, previous CABG, previous PCI, } \\
2 \text { or more previous cardiovascular operations, } \\
\text { hypertension, immunosuppressive therapy, } \\
\text { peripheral vascular disease, unstable angina, left } \\
\text { main coronary artery disease, triple-vessel disease, } \\
\text { cerebrovascular disease, previous cerebrovascular } \\
\text { accident, diabetes, urgent status, congestive heart } \\
\text { failure (NYHA class IV or classes III), atrial } \\
\text { fibrillation, ejection fraction, chronic lung disease, } \\
\text { dialysis, creatinine level, and previous MI. }\end{array}$ \\
\hline $\begin{array}{l}\text { Kohsaka and colleagues, }{ }^{28} \\
2016\end{array}$ & $\begin{array}{l}\text { 1:1 matching nearest-neighbor matching } \\
\text { caliber width of } 0.2 \mathrm{SD}\end{array}$ & Lower & $\begin{array}{l}\text { Age, sex, body mass index, smoker, diabetes, chronic } \\
\text { kidney disease, hyperlipidemia, hypertension, } \\
\text { cerebrovascular disease, carotid disease, atrial } \\
\text { fibrillation, respiratory disability, peripheral } \\
\text { arterial disease, previous PCI, previous MI, } \\
\text { unstable angina, LVEF }<50 \% \text {, heart failure, } \\
\text { cardiogenic shock, aspirin, anticoagulants, statins, } \\
\text { angiotensin-converting enzyme, triple-vessel } \\
\text { disease, left main disease, surgery status, } \\
\text { reoperation. }\end{array}$ \\
\hline
\end{tabular}

PSA, Propensity score analysis; NYHA, New York Heart Association; $L V E F$, left ventricular ejection fraction; IABP, intra-aortic balloon pump; $M I$, myocardial infraction; $P C I$, percutaneous coronary intervention; $C A B G$, coronary artery bypass grafting. 